\title{
Wenchuan earthquake fault and seismic disaster*
}

\author{
Boming Zhao ${ }^{1, *}$ and Xiwei $\mathrm{Xu}^{2}$ \\ ${ }^{1}$ School of Civil Engineering, Beijing Jiaotong University, Beijing 100044, China \\ ${ }^{2}$ National Center for Active Fault Studies, Institute of Geology, China Earthquake Administration, \\ Beijing 100029, China
}

\begin{abstract}
Major cases of the $M_{\mathrm{S}} 8.0$ Wenchuan earthquake are obtained through field investigations of the epicenter and high-intensity areas, and the relationships among earthquake faults, ground motion and earthquake disasters near fault zones are analyzed. Both strong deformation and ground rupture lead to significant damages of the buildings, indicating that it is necessary to keep safe distance away from active faults and to take other necessary measures. There are two reasons for that the buildings near the surface rupture zones have withstood in the strong earthquake, other than their seismic resistance capacities, with the first being the site condition, and the second the reduced effective stress and low rupture velocity. The forms of structural damages are complex in the fault areas, with shear failure and tensile and compressive damages. Those structures in urban areas that have used qualified materials and followed the building codes performed well in the earthquake. Survey results also indicate that structures of flexible materials may show better seismic performance.
\end{abstract}

Key words: Wenchuan earthquake; earthquake fault; seismic disaster; strong ground motion CLC number: P315.9 Document code: A

\section{Introduction}

According to China Earthquake Administration (2008), the Wenchuan earthquake with a magnitude of $M_{\mathrm{S}} 8.0$ at a focal depth of $14 \mathrm{~km}$, or a magnitude of $M_{\mathrm{S}} 8.0$ at depth of $19 \mathrm{~km}$ by USGS(2008), occurred in the middle of the napped tectonic zone of the Longmenshan. Wenchuan, Beichuan, Qingchuan and other areas suffered from severe destructions. Chen et al (2008) first reported a source model and rupture distribution of the faults based on source inversion, and an average slip width of about $5 \mathrm{~m}$. The emergency field survey ( $\mathrm{Xu}$ et al, 2008) showed that the earthquake caused the Beichuan-Yingxiu fault and the Guanxian-Jiangyou fault ruptured simultaneously.

It is important to interpret the relationship among complex fault, earthquake ground motion, and building damage. Using the information from field survey, this paper introduces the cases of the fracture zones in the near-fault regions and other regions with serious disasters. The correlations and basic characteristics of the

\footnotetext{
* Received 27 February 2009; accepted in revised form 17 March 2009; published 10 April 2009.

^ Corresponding author. e-mail: bmzhao@bjtu.edu.cn
}

earthquake disasters are analyzed, so as to provide references for earthquake resistance and disaster relief. Shown in Figure 1 are the investigation sites and surface ruptures of the Wenchuan earthquake region.

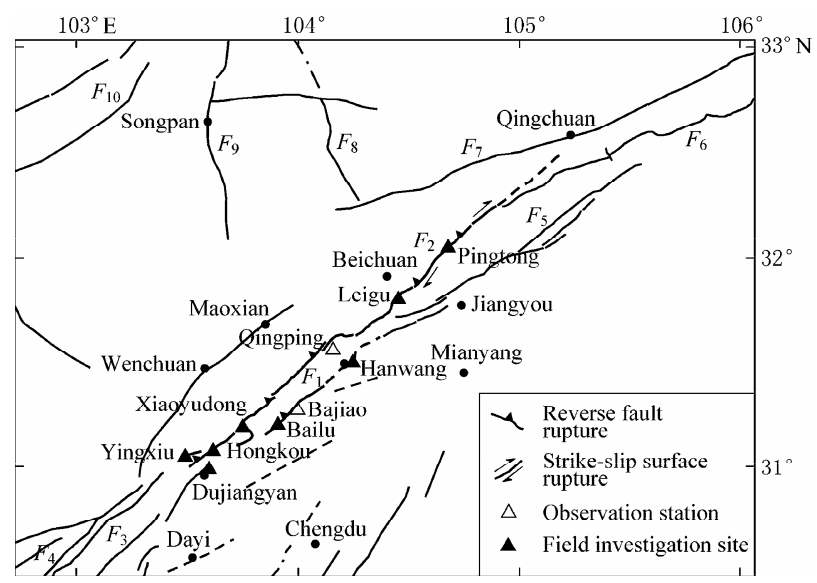

Figure 1 Investigation sites and surface rupture of the Wenchuan earthquake region. $F_{1}$. Guanxian-Jiangyou fault; $F_{2}$. Beichuan-Yingxiu fault; $F_{3}$. Shuangshi-Dachuan fault; $F_{4}$. Yanjing-Wulong fault; $F_{5}$. Jiangyou-Guangyuan fault; $F_{6}$. Chaba-Linyansi fault; $F_{7}$. Qingchuan fault; $F_{8}$. Huya fault; $F_{9}$. Minjiang fault; $F_{10}$. Longriba fault. 


\section{Fault and damage investigation}

\subsection{Near-fault region}

Near-fault region generally refers to the region less than $15 \mathrm{~km}$ away from the fault. According to the survey, earthquake damage is very intensive in near-fault region. Through inspecting serious damage areas of the towns such as Yingxiu, Hongkou, Xiaoyudong, Hanwang, Leigu and Pingtong, it is found that destruction of buildings took place extensively in these areas. In the light of post-disaster assessment, the towns of Yingxiu and Leigu are identified as XI degree, others are identified as $\mathrm{X}$ degree. Photo 1 shows places of the town of Hanwang where large scale areas are destroyed (on the right side) and a corner of a station. It can be seen that the residential buildings have serious damage and collapse, while station of the frame construction has good seismic performance. Photo 2 shows that serious shear failure takes place in the teaching building of the town of Yingxiu. On the wall shows typical X cracks caused by horizontal force. Photos 3 and 4 show the collapse of the teaching building with prefabricated floors and stairs of Beichuan middle school and Pingtong middle school, respectively. Owing to lacking of the connected measures, the masonry construction leads to the whole damage. The mixed structure of underlying framework is also destroyed at a large scale. The failure of concrete materials and shoddy construction quality are important factors for it (Photos 5 and 6).

\subsection{Near the surface rupture zone}

The two teaching buildings of Bailu middle school are separately located in two sides of the rupture zone of Guanxian-Jiangyou, only a few meters away from the rupture zone (Photo 7). According to measurements at the scene, the width of fault deformation belt is about 18-20 m, vertical displacement is more than $2 \mathrm{~m}$, and

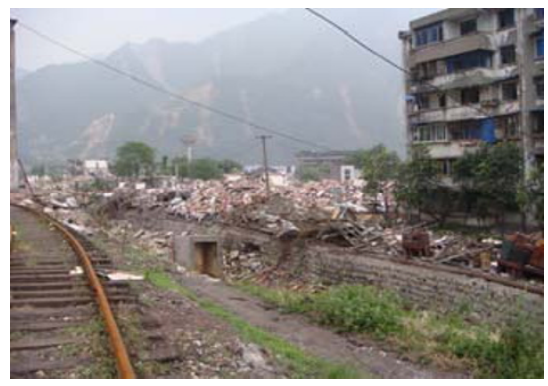

Photo 1 Damaged residential areas

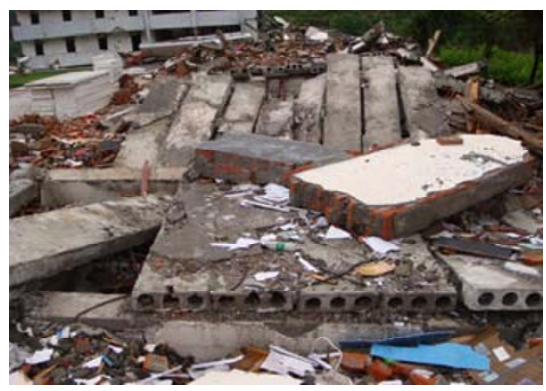

Photo 4 The same as Photo 3

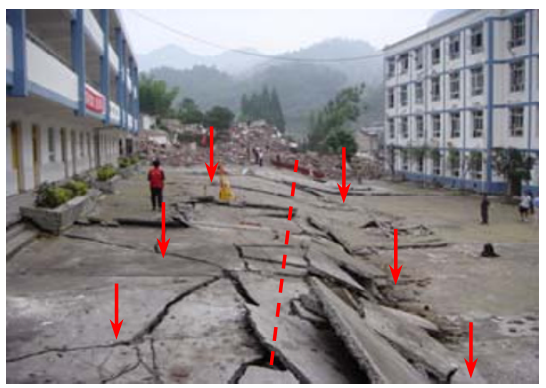

Photo 7 School buildings and surface rupture
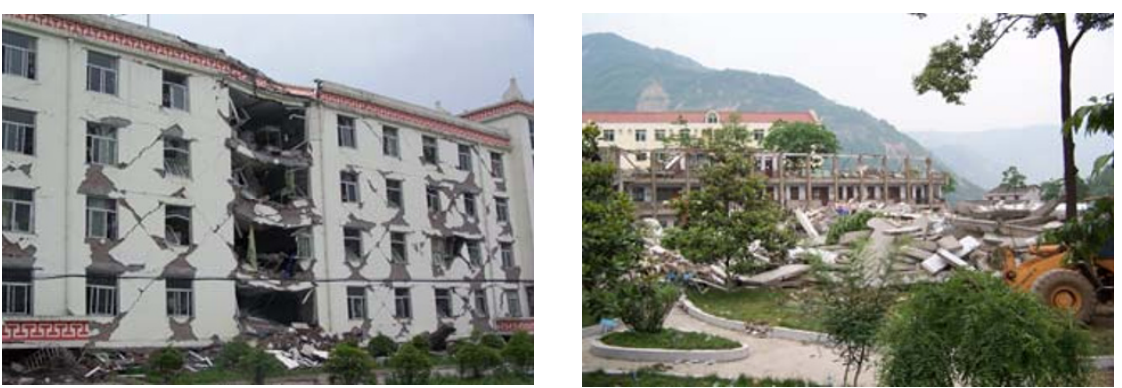

Photo 2 Damaged teaching building

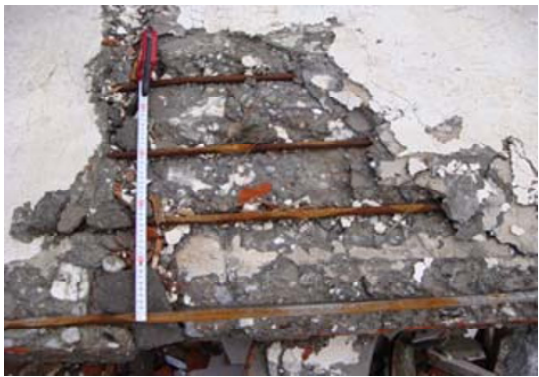

Photo 5 Substandard building materials and construction

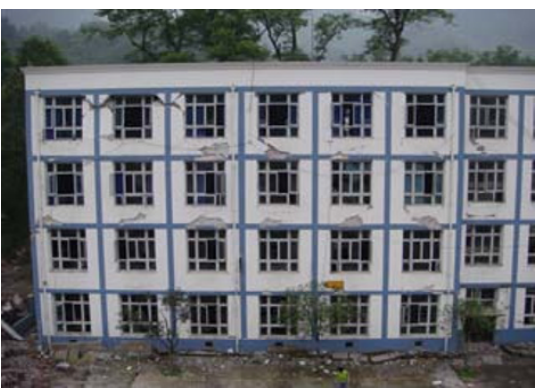

Photo 8 Damaged old teaching building on foot wall
Photo 3 Construction using prefabricated parts

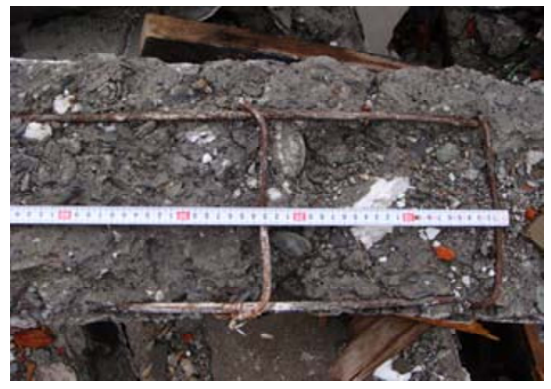

Photo 6 The same as Photo 5

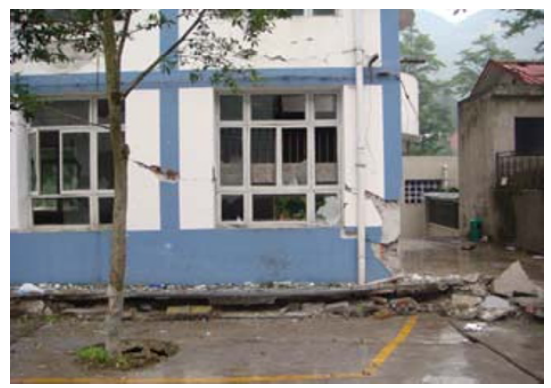

Photo 9 Horizontal cracks on wall 


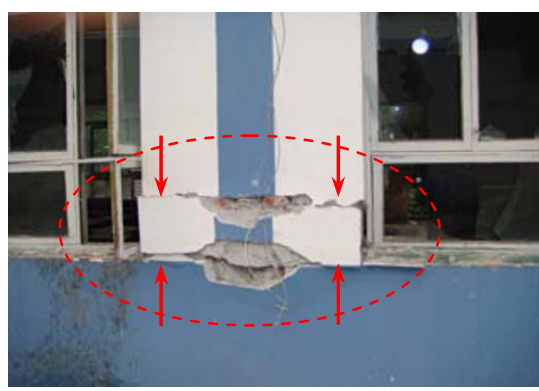

Photo 10 The same as Photo 9

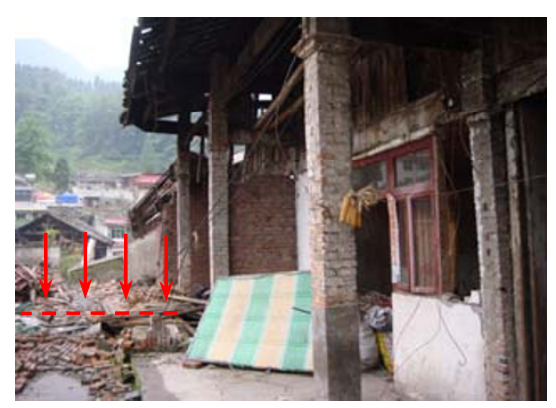

Photo 13 No-collapse old house on hanging wall

the shortening distance $1.8 \mathrm{~m}$. The building lying at the right side of Photo 7 is a four-story brick structure, and the main structure is seriously damaged but do not collapse. The building was completed in the early 1990's in accordance with the norms for the design and construction. Obvious reinforced tension appears in the structural columns of the first floor (Photos 9 and 10) and necking damage occurred in that building (Photos 11 and 12). All show that the building is substantially up and down, resulting in failure of the masonry and concrete structure. The building lying at the left side of Photo 7 is a there-story brick structure. The teaching building is not destroyed owing to following the revised norms of the new seismic design in 2001.

Investigation suggests that the buildings lying on the fault rupture belt almost completely collapse, while most of the buildings near the fault rupture do not collapse, even the folk houses only a few meters away from the rupture belt have also withstood (Photos 13). Although the physiognomy and geological conditions in the region bring much challenge to the construction site, many buildings constructed on the hill are not broken down or damaged seriously on a large scale. Photos of 13 and 14 are good examples of no-collapsed buildings on hanging wall.

\section{Analysis}

The survey shows that earthquakes distribute

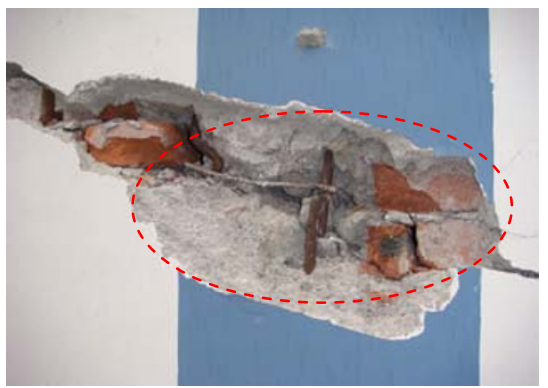

Photo 12 The same as Photo 11

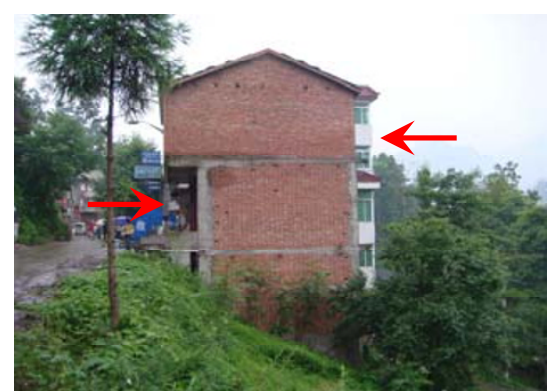

Photo 14 No-collapse two multistory building on slope

widely in near-fault region (within 10-15 km away from the fault), especially in the submountainous region. These regions are either mountainous areas near the fault, in which ground shakes strongly, or the junctions of the basin and mountainous areas, and the bad conditions play a destructive role to the buildings.

Seismic records also show that ground motion in these regions reaches a very high magnitude. For the strong ground motion station of Shifang-Bajiao located in the piedmont region, far away from the central fault, the north-south component of its acceleration is 585.7 $\mathrm{cm} / \mathrm{s}^{2}$, while the peak of vertical component is 632.9 $\mathrm{cm} / \mathrm{s}^{2}$. The strong and complex ground motion leads to serious earthquakes in a wide range of piedmont regions. Due to complex ground motion, type of structure, space effect, building material and other factors, the forms of the structural damage major in shear failure and tensional-compressional failure. As basic material, reinforced concrete and masonry materials are likely to cause brittle fracture as a result of the unreasonable structure forms.

According to the earthquake observation records nearest to the fault (about $80 \mathrm{~m}$ ) (Housner and Trifnac, 1967), it can be seen that the process of dislocation near the rupture zone is relatively slow, up to a few seconds. When the displacement reaches its peak, it would make the ground surface failure and the unsuccessful ground motion effect reduce greatly. In this case, the major 
damage would shift from vibration damage to displacement damage. The acceleration caused by vertical movement would make the building failure by relatively large tension or compression.

Somerville (2003) indicated that the ground motion generated by buried rupture with period around $1 \mathrm{~s}$ is larger than that generated by surface rupture. Figure 2 shows ratio of response spectra of recorded ground motions to that of an empirical attenuation relationship for surface rupture earthquakes. Kagawa et al (2004a, b) analyzed the macroscopic fault rupture parameters, i.e., the total rupture area $A_{0}$, the stress drop $\sigma_{0}$ and the ratio of the combined asperity area to the fault area $A_{\mathrm{a}} / A_{0}$, and found that effective stress drops, asperity slip contrast and slip velocity are lower for the cases of surface rupture earthquake than buried rupture earthquake (Table 1). The results suggest that the buildings are damaged mainly by the effect of surface dislocation, rather than by the strong ground motion.

To sum up, the near-fault region is the main destruction area due to strong ground shaking with complex field effect, where earthquake disasters distribute widely. When the displacement damage takes place near the
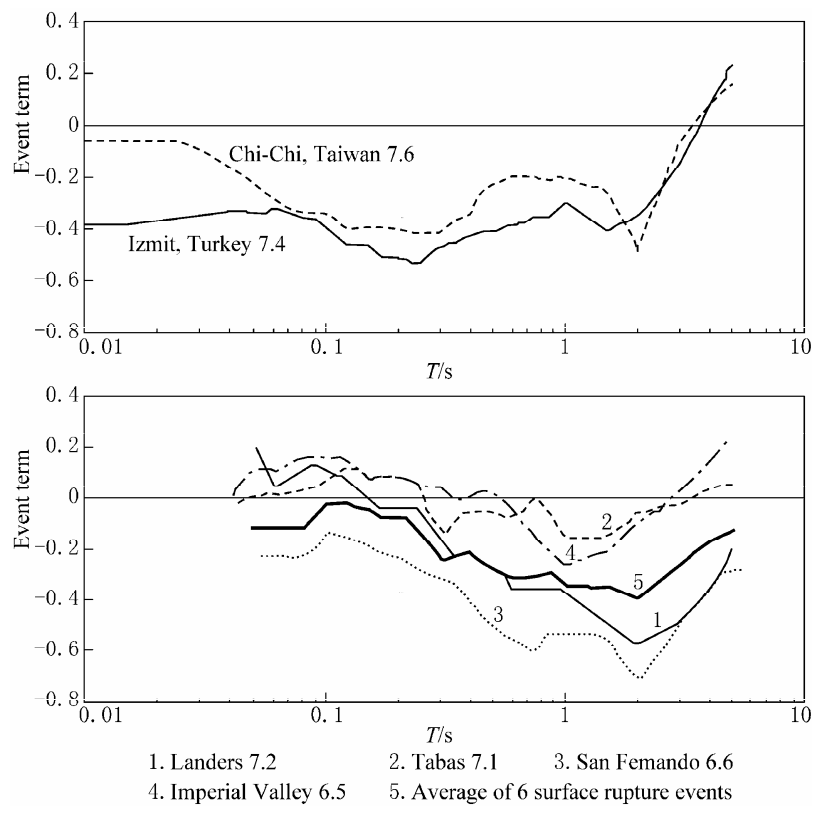

Figure 2 Ratio of response spectra of recorded ground motions to that of an empirical attenuation relationship for the cases of surface rupture earthquake. The zero line represents the level of the empirical attenuation relationship (from Abrahamson and Silva, 1997).

Table 1 Scaling parameters for individual asperities (Kagawa et al, 2004a).

\begin{tabular}{ccccc}
\hline & & Stress drop $\sigma_{0} / \mathrm{MPa}$ & Asperity slip contrast $D_{\mathrm{a}} / D_{0}$ & Effective slip velocity $V_{\text {eff }} / \mathrm{cm} \cdot \mathrm{s}^{-1}$ \\
\hline Surface break fault & Shallow asperities & $6.5 \pm 4.6$ & $2.1 \pm 0.4$ & $133 \pm 60$ \\
& Deep asperities & $23.6 \pm 15.2$ & $2.0 \pm 0.3$ & $286 \pm 164$ \\
Buried fault & Deep asperities & $23.7 \pm 14.5$ & $2.4 \pm 0.8$ & $286 \pm 164$ \\
\hline
\end{tabular}
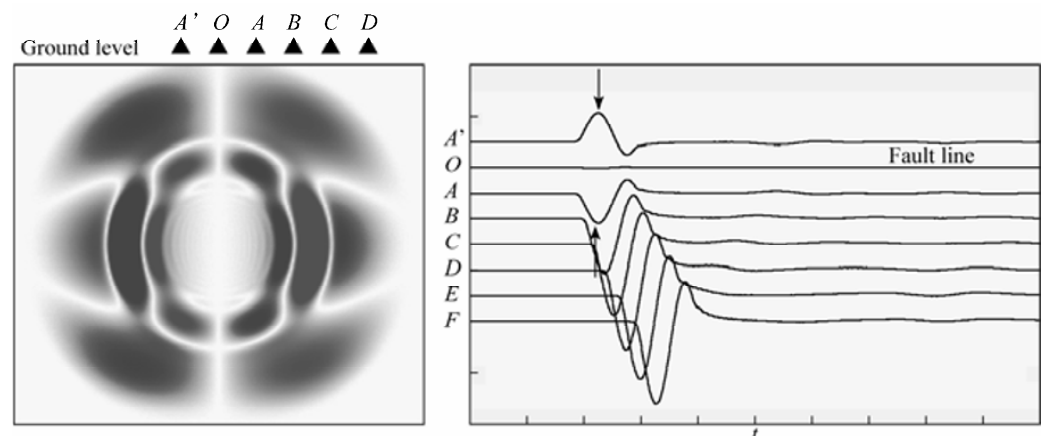

Figure 3 Test simulation of ground displacement based on a simple model. Left indicates source rupture and wave propagation, right indicates synthetic displacement of vertical component at site array cross the fault $O$.

surface rupture zone, landslides and other geological disasters are very serious. The results of field investigation about Bailu are good examples for it (Photos from 7 to14). The vertical displacement situation is simulated at the rupture moment of the fault sources rupture. As shown in Figure 3, $O$ is the fault trace, and $A$ ' and $A$ are the observation points on both sides of the fault, respec- tively. The simulation shows the points $A$ ' and $A$ on both sides of the fault move up and down simultaneously. At the same time, displacement near the fault is smaller. With the wave spreading toward the external points $B, C$, and $D$ point by point, the displacement increases.

The resistance levels of the areas discussed in this paper are all located in the zone where seismic peak 
ground acceleration is $0.1 \mathrm{~g}$ according to the Seismic Ground Motion Parameter Zonation Map of China (GB18306-2001), equivalent to basic VII degree. According to the norms for all the types of buildings located in VIII degree area, the buildings are not expected to collapse. The intensity of the Wenchuan earthquake is IX-XI, so it is inevitable that most buildings collapse and are severely damaged. Especially in the rural areas, due to no earthquake-proof actions carried out, extensive damages take place, which is directly related to no earth-

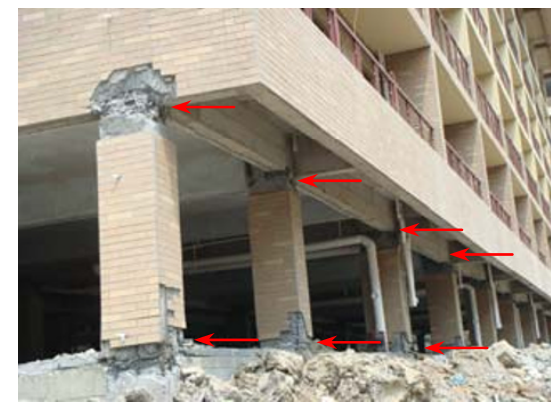

Photo 15 Damaged multistory building

\section{Discussion and conclusions}

The paper presents the main cases of seismic disaster of the Wenchuan $M_{\mathrm{S}} 8.0$ earthquake by field investigations about epicentral area and high-intensity areas, analyzes and discusses the relationship among earthquake faults, ground motion and earthquake disasters near fault zone. Firstly, intensive deformations and ground rupture along the earthquake fault lead to obvious damages to the buildings, so it is necessary to keep the safe distance away from active fault or take other measures. Secondly, there are two reasons for that the buildings near the surface rupture zones have withstood in the strong earthquake, other than their performance of seismic resistance, with the first being the good site condition, that is, most of them locate at hard sites or on bedrock in the surface rupture zone; and the second the reduced effective stress and low rupture velocity, that is, effective stress drop and low rupture velocity may exist in the shallow asperities, resulting in a relatively lower ground motion at the period about $1 \mathrm{~s}$. Thirdly, the forms of structural damages are complex in the fault areas, with shear failure, tensile and compressive damages. Those structures in urban areas, which have used qualified materials and followed the building codes, performed well in the earthquake. And survey results also indicate that structures of flexible materials may show quake-proof and the quality of the building materials. In urban areas, buildings designed in accordance with the seismic design code show better seismic performance, mostly achieving the goal of earthquake-proof. However, there are individual cases. For instance, the use of rigid structure causes brittle damage of concrete structure (Photo 15). Photo 16 shows upper part of masonry structure is apparently damaged compared with that of the steel structure.

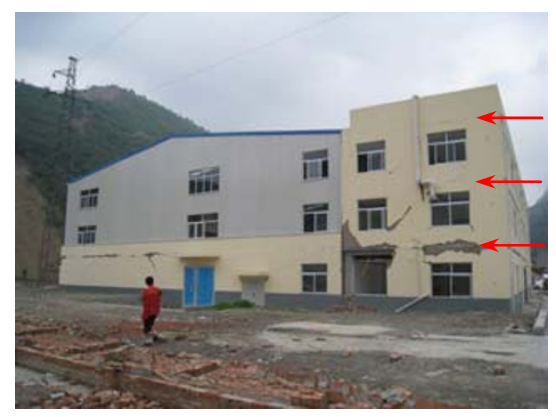

Photo 16 Damaged plant

better seismic performance.

Acknowledgements This paper is supported by National Natural Science Foundation of China (No. 40674016 and No. 50478060), the Seismic Industry Foundation of Ministry of Science and Technology of China ([2007]203/8-53) and the scientific field investigations project on the $M_{\mathrm{S}} 8.0$ Wenchuan earthquake of China Earthquake Administration.

\section{References}

China Earthquake Administration (2008). Seismological parameters for the $M_{\mathrm{S}} 8.0$ Wenchuan earthquake, Sichuan. http://www.csi.ac.cn/sichuan/sichuan080512_cs1.htm (in Chinese).

Abrahamson N A and Silva W J (1997). Empirical response spectral attenuation relations for shallow crustal earthquakes. Seism Res Lett 68: 94-127.

Chen Y T, Xu L S, Zhang Y, Du H L, Feng W P, Liu C and Li C L (2008). Report on the great Wehchuan earthquake source of May 12, 2008. http://www.csi.ac.cn/sichuan/chenyuntai.pdf (in Chinese).

Housner G W and Trifnac M D (1967). Analysis of accelerograms-Parkfield earthquake. Bull Seism Soc Amer 57: 1 193-1 220.

Kagawa T, Irikura K and Somerville P G (2004a). Differences in ground motion and fault rupture process between the surface and buried rupture earthquakes. Earth Planets Space 56: 3-14.

Kagawa T, Zhao B M, Miyakoshi K and Irikura K (2004b). Modeling of the 3D basin structures for seismic wave simulations based on available information on the target area: Case study of the Osaka Basin, Japan. Bull Seism Soc Amer 94: 1 353-1 368.

Somerville P G (2003). Magnitude scaling of the near fault rupture directivity pulse. Phys Earth Planet Int 137: 201-212.

USGS (2008). Magnitude 7.9 — Eastern Sichuan, China. http://neic.usgs.gov/ neis/eq_depot/2008/eq_080512_ryan. 